\title{
OPTIC NERVE GLIA SECRETE A LOW-MOLECULAR-WEIGHT FACTOR THAT STIMULATES RETINAL GANGLION CELLS TO REGENERATE AXONS IN GOLDFISH
}

\author{
J. M. SCHWALB, ${ }^{*}$ M-f. GU, ${ }^{*}$ C. STUERMER $\dagger$ M. BASTMEYER, $\dagger$ G-f. HU \\ N. BOULIS, ${ }^{*}$ N. IRWIN*§ and L. I. BENOWITZ* $+\S \| \uparrow$
}

*Department of Neurosurgery, Children's Hospital (Boston), §Department of Surgery, ॥Program in Neuroscience, and \$Center for Biochemical and Biophysical Sciences and Medicine, Harvard Medical School, Boston, MA 02115, U.S.A.

$\dagger$ Fakultät Biologie, Universität Konstanz, Konstanz, Germany

\begin{abstract}
The ability of lower vertebrates to regenerate an injured optic nerve has been widely studied as a model for understanding neural development and plasticity. We have recently shown that, in goldfish, the optic nerve contains two molecules that stimulate retinal ganglion cells to regenerate their axons in culture: a low-molecular-weight factor that is active even at low concentrations (axogenesis factor-1) and a somewhat less active polypeptide of molecular weight 10,000-15,000 (axogenesis factor-2). Both are distinct from other molecules described previously in this system. The present study pursues the biological source and functional significance of axogenesis factor-1. Earlier studies have shown that cultured goldfish glia provide a highly favorable environment for fish or rat retinal ganglion cells to extend axons. We report that the glia in these cultures secrete high levels of a factor that is identical to axogenesis factor- 1 in its chromatographic properties and biological activity, along with a larger molecule that may coincide with axogenesis factor-2. Axogenesis factor-1 derived from either goldfish glial cultures or optic nerve fragments is a hydrophilic molecule with an estimated molecular weight of 700-800. Prior studies have reported that goldfish retinal fragments, when explanted in organ culture, only extend axons if the ganglion cells had been "primed" to begin regenerating in vivo for one to two weeks. However, axogenesis factor-1 caused the same degree of outgrowth irrespective of whether ganglion cells had been induced to regenerate new axons in vivo. Moreover, ganglion cells primed to begin regenerating in vivo continued to extend axons in culture only when axogenesis factor- 1 was present.

In summary, this study shows that glial cells of the goldfish optic nerve secrete a low-molecular-weight factor that initiates axonal regeneration from retinal ganglion cells
\end{abstract}

Key words: axogenesis, trophic factors, vision, neuronal differentiation, cell culture.

Axonal development and regeneration are governed by a complex set of interactions between the neuron and its environment. ${ }^{1,10,15,30,34}$ Neurons of the mature mammalian CNS fail to regenerate their axons after injury, which can be attributed in part to inhibitory molecules expressed by oligodendrocytes. ${ }^{9,25,28,32}$ In contrast, fish and amphibia retain the capacity to regenerate damaged CNS pathways throughout life, the most prominent example of which is their ability to regenerate an injured optic nerve. ${ }^{16,21,37}$ Glial cells of the goldfish optic nerve express high levels of

TTo whom correspondence should be addressed, at: Labs for Neuroscience Research in Neurosurgery, Children's Hospital, Enders 312, 300 Longwood Avenue, Boston, MA 02115 , U.S.A.

Abbreviations: AF-1, axogenesis factor-1; AF-2, axogenesis factor-2; FCS, fetal calf serum; GCM, glial conditioned medium; HEPES, $N$-2-hydroxyethylpiperazine- $N^{\prime}-2$ ethanesulfonic acid; HPLC, high-performance liquid chromatography; ONCM, optic nerve conditioned medium; PBS, phosphate-buffered saline. cell surface and extracellular matrix factors that may contribute to promoting axonal regeneration, and little or none of a partially characterized inhibitory molecule that is present on the surface of oligodendrocytes in mammals. ${ }^{2-7,19,20,39,40}$ In addition, nonneuronal elements of the goldfish optic nerve secrete a variety of soluble factors that are likely to contribute to the regenerative process. $8.11,12,14,18,27,31$

We have recently shown that two previously uncharacterized factors that are present in the optic nerve exert direct neurite-promoting effects on goldfish retinal ganglion cells: the more potent of the two, axogenesis factor-1 (AF-1), is a small molecule of molecular weight $700-900$; the second, AF-2, is a polypeptide of molecular weight $10,000-15,000$ that is somewhat less active in cultures. ${ }^{35}$ The previous study had suggested that AF-1 and AF-2 may be specific to the nervous system, since factors derived from several non-neural tissues failed to promote axonal outgrowth. ${ }^{35}$ However, since we utilized pieces of optic nerve as the source of the factors, we were able to 


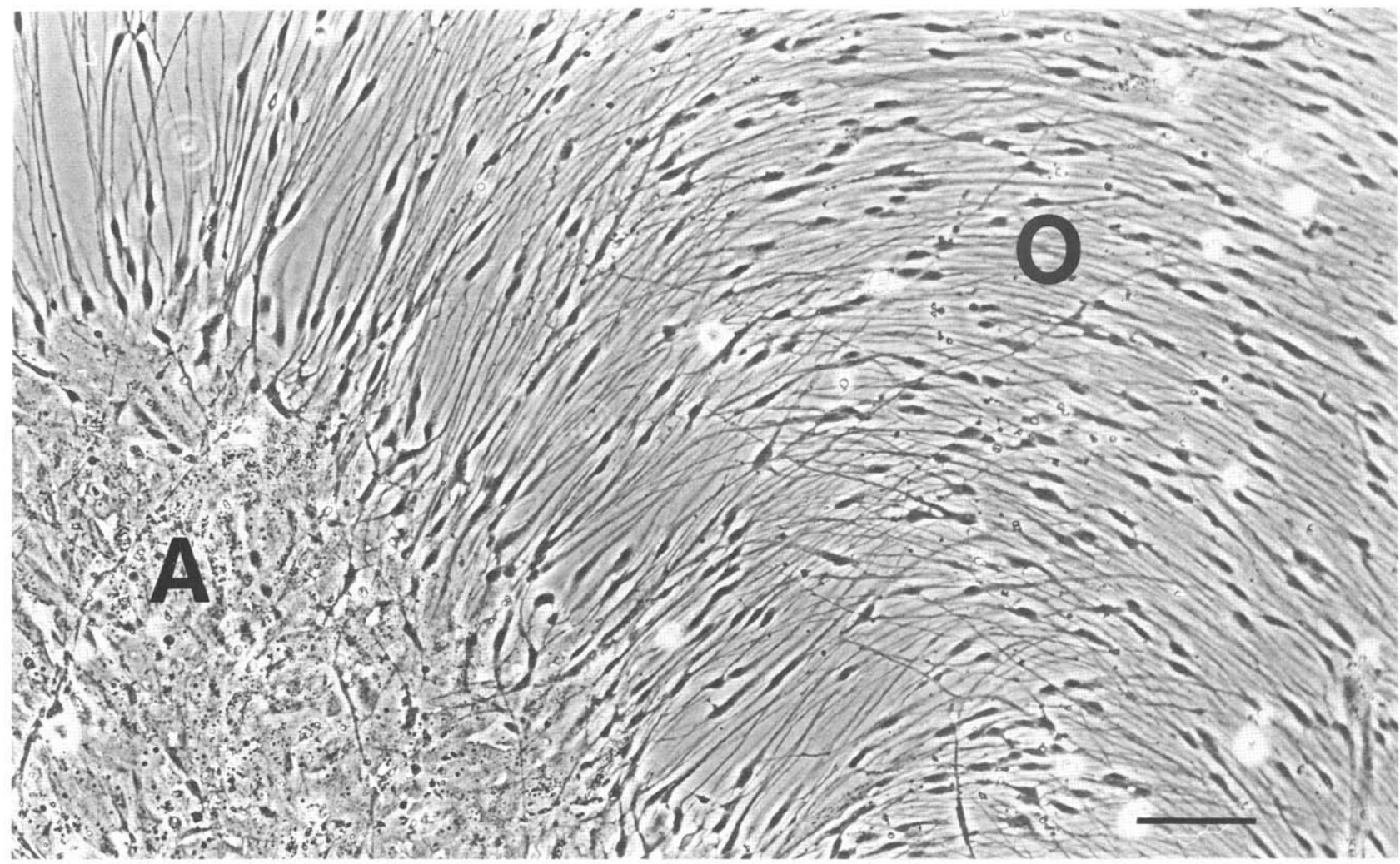

Fig. 1. Phase contrast micrograph of a primary glial cell culture from the goldfish optic nerve after four weeks in vitro. The cultures are characterized by two cell types that occupy separate clusters. Elongated cells have previously been shown to be oligodendrocytes $(\mathrm{O})$, whereas the clusters of compact cells represent astrocytes (A) (see Refs 2-4). Scale bar $=100 \mu \mathrm{m}$.

determine whether these molecules arise from degenerating axons, macrophages or glial cells. In addition, since the experimental procedure required dissection of the nerve into small fragments to obtain appreciable levels of the factors, it was not clear whether they are truly secreted or are released by cell lysis. To address these questions, we have investigated whether goldfish glia, when grown in long-term dissociated cultures, secrete the principal factors found in our previous study.

A second issue that we investigated was the role of the novel factors in initiating axonal outgrowth. Prior studies had shown that fragments of the goldfish retina will only extend axons in culture if the ganglion cells had been "primed" by first sectioning the optic nerve and allowing the regenerative response to develop for one to two weeks in vivo before being explanted; in contrast, unprimed retinal explants have generally been found to exhibit little outgrowth, even after several days in culture. ${ }^{13,17,22-24.38}$ Since these explants do not normally contain cells of the optic nerve, it is conceivable that it was the absence of AF-1 and/or AF-2 which had prevented intact retinal fragments from regenerating in culture. We have therefore compared the growth of primed and unprimed retinal ganglion cells in culture in the presence and absence of the factors.

\section{EXPERIMENTAL PROCEDURES}

Dissociated retinal cultures

To prepare dissociated retinal cultures, ${ }^{35}$ Comet variety goldfish (3-4", Mt Parnell Fisheries, Ft Louden, PA,

Fig. 2. Neurons of the goldfish retina extend axon-like processes in response to AF-1. (a) Dissociated cells of the goldfish retina maintained for six days with control media. (b) Factors secreted by cultured optic nerve glia (i.e. GCM, diluted 1:20 in this instance) stimulate retinal neurons to extend long processes. The round or oval cells $10-17 \mu \mathrm{m}$ across which extend one to two long processes in response to AF-1 were shown by retrograde labeling to be ganglion cells ${ }^{35}$ (c, d) Axonal outgrowth in response to the factors isolated from GCM (c) and ONCM (d) by sequential ultrafiltration, reverse-phase HPLC and size-exclusion HPLC. 


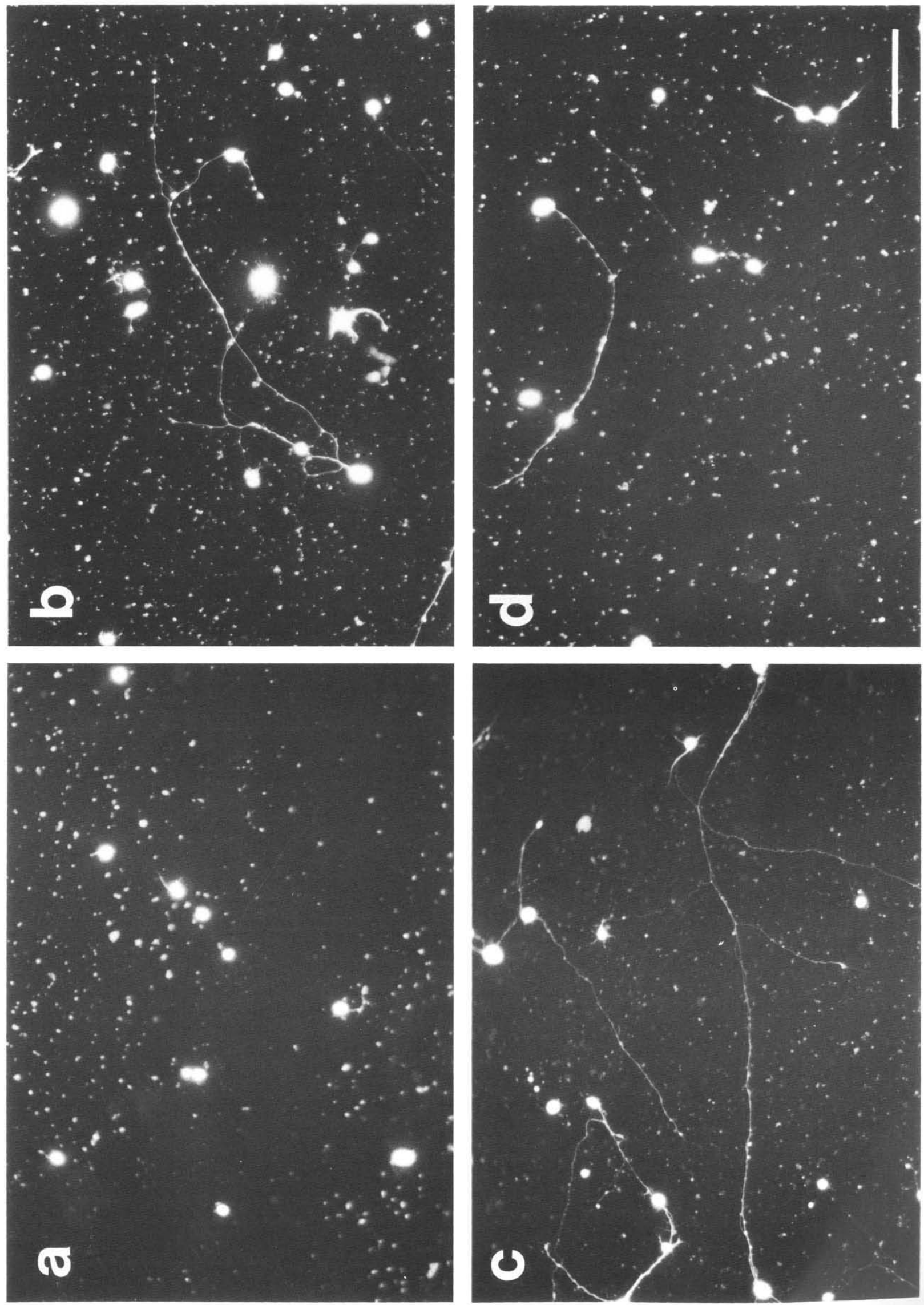


Table 1. Activity of factors secreted by optic nerve glia

\begin{tabular}{lcccc}
\hline Sample & Fraction & $\begin{array}{c}\text { Concentration } \\
(\%)\end{array}$ & Mean \pm S.E.M.** & $\begin{array}{c}\text { Difference } \\
\text { fom negative } \\
\text { controls } \dagger\end{array}$ \\
\hline L-15+ Medium E & - & - & $0.00 \pm 0.03$ & - \\
ONCM & total & 10 & $1.00 \pm 0.06$ & $P<0.001$ \\
GCM & $<3000$ & 1 & $0.61 \pm 0.05$ & $P<0.001$ \\
GCM & $<3000$ & 10 & $1.07 \pm 0.21$ & $P<0.01$ \\
GCM & $>3000$ & 1 & $0.36 \pm 0.12$ & $P<0.05$ \\
GCM & $>3000$ & 10 & $0.84 \pm 0.07$ & $P<0.001$ \\
\hline
\end{tabular}

*Based upon four replicates; all experiments were blind. Data were normalized by subtracting the growth in negative controls (cultures treated with Medium E + L-15 only) and dividing by the net growth in the positive controls (cultures treated with factors secreted by optic nerve fragments).

$\dagger$ Two-tailed $t$-tests.

U.S.A.) were dark-adapted for at least $30 \mathrm{~min}$, anesthetized by chilling to $4{ }^{\circ} \mathrm{C}$ and killed by cervical transection. The eyes were removed and retinas were dissected free from the sclera, lens and major blood vessels under $\times 25$ magnification. ${ }^{23}$ Four retinas were rinsed briefly in $70 \%$ ethanol and culture media, then incubated in $5 \mathrm{ml}$ of sterile digestion solution [100 units of papain (Worthington) plus $2.5 \mathrm{mg}$ L-cysteine (Sigma Chemical Co., St Louis, MO, U.S.A.) in HEPES-buffered Liebovitz L-15 media (Gibco), pH 7.4] for $45 \mathrm{~min}$ at room temperature. Successive triturations in sterile L-15 resulted in a single-cell suspension enriched in ganglion cells. To each well of a 24-well tissue culture dish (Costar, Cambridge, MA, U.S.A., coated with poly-L-lysine, Sigma, molecular weight $>300,000$ ), we added $50 \mu \mathrm{l}$ of the cell suspension and $200 \mu 1$ of $2 \times$ Medium E [final concentrations: $20 \mathrm{nM}$ hydrocortisone, $1 \mathrm{mM}$ kainurinate, $100 \mu \mathrm{M}$ putresceine, $20 \mathrm{nM}$ progesterone, $30 \mathrm{nM}$ selenium, $0.3 \mathrm{nM}$ 3,3',5-triiodo-L-thyronine, $\quad 50 \mu \mathrm{g} / \mathrm{ml}$ holotransferrin, $150 \mathrm{U} / \mathrm{ml}$ catalase, $60 \mathrm{U} / \mathrm{ml}$ superoxide dismutase, $1 \%$ bovine serum albumin (Type $\mathrm{V}$, with free fatty acids), $10 \mu \mathrm{g} / \mathrm{ml}$ gentamycin, $5 \mu \mathrm{g} / \mathrm{ml}$ insulin and $15 \mathrm{mM}$ HEPES (all reagents from Sigma), titrated to $\mathrm{pH} 7.4$ and filter-sterilized]. Finally, wells received an additional $150 \mu 1$ containing either an experimental sample to be tested for biological activity, a negative control sample (L-15) or a positive control (a previously validated sample of conditioned media). Experimental and control samples were distributed on the plate in a randomized fashion. Plates were incubated in a dark humidified tank for six days at room temperature before being evaiuated.

For the priming experiments, goldfish were anesthetized with $0.5 \mathrm{mg} / \mathrm{ml}$ 3-aminobenzoic acid ethyl ester (Sigma) and the optic nerves were crushed 1-2 mm behind the orbit. Retinas were isolated 10-14 days later and dissociated cultures were prepared as described above.

\section{Quantification of neurite outgrowth}

After six days in culture, the medium was removed and replaced with the vital dye 5,6-carboxyfluorescein diacetate $(0.1 \mathrm{mg} / \mathrm{ml}$; Sigma) in phosphate-buffered saline (PBS) for $10 \mathrm{~min}$. The dye solution was then removed and replaced with PBS. Cultures were examined at $\times 200$ magnification under fluorescent illumination, recording (i) the number of viable cells in an area one microscope field wide and one well radius long (typically containing $150-250$ cells), and (ii) the number of viable cells within this region that matched the established criteria for retinal ganglion cells (round or oval cells, $10-17 \mu \mathrm{m}$ across, extending either one or two long processes of uniform caliber ${ }^{35,36}$ ) and which extended axons $>$ five cell diameters in length. The person evaluating the cultures was blind to the experimental conditions in each well. Neurite outgrowth was calculated as the number of

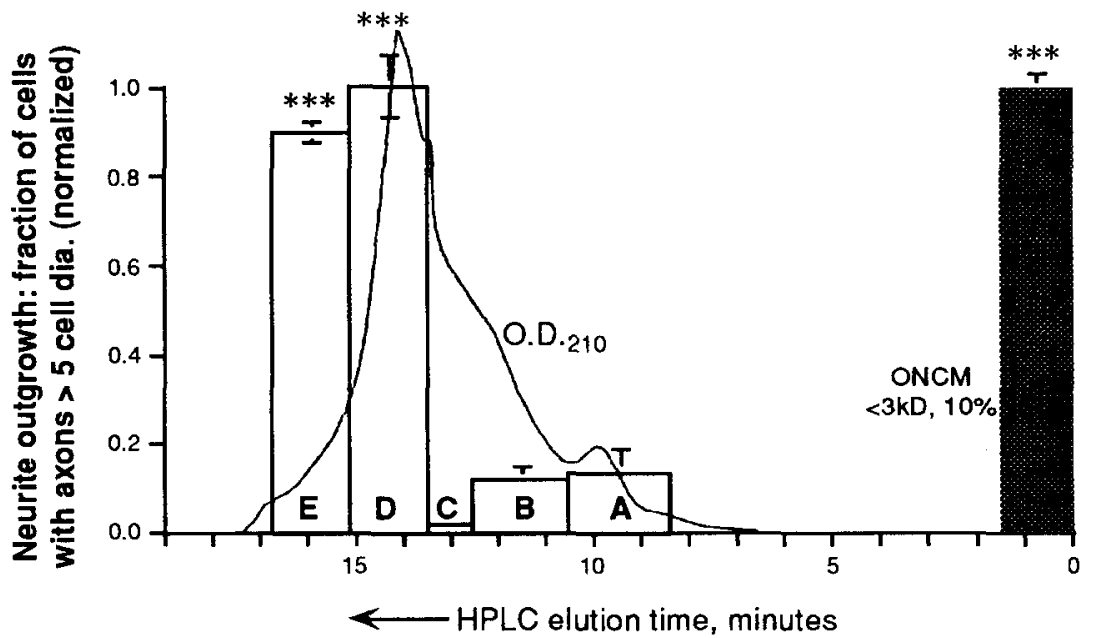

Fig. 3. Initial separation of GCM reveals a peak of activity. The low-molecular-weight fraction of GCM, when subjected to size-exclusion chromatography, yields a complex mix of components. In the bioassay, fractions $\mathrm{D}$ and $\mathrm{E}$, which elute between 14 and $16 \mathrm{~min}$, contain the neurite-promoting activity (open bars \pm S.E.M.; fractions tested blind in quadruplicate at $10 \%$ concentrations; ${ }^{* * *}$ difference from negative controls significant at $P<0.001$ ). 
cells with neurites $>$ five cell diameters divided by the total number of viable cells. Where appropriate, data were normalized by subtracting the average growth in the negative controls and dividing by the average net growth in the positive controls. Data are presented as the mean \pm S.E. for four to eight replicates. Statistical analyses were performed using StatView 4.1 (Abacus Concepts, Berkeley, CA, U.S.A.). All results shown are representative of at least three independent experiments.

\section{Glial conditioned medium}

Glial cultures were prepared as described previously. ${ }^{3}$ Two to three weeks after transecting the optic nerve behind the orbit, the optic nerve and tract were dissected free of connective tissue, cut into small fragments and explanted onto polylysine/laminin-coated, $35 \mathrm{~mm}$ culture dishes with Ham's F-12 medium [Gibco/BRL, Gaithersburg, MD, U.S.A., supplemented with $10 \%$ fetal calf serum (FCS), $0.4 \%$ methylcellulose (Dow) and $50 \mu \mathrm{g} / \mathrm{ml}$ gentamycin] at room temperature in a humidified chamber. Glial cells migrate off the explants, multiply in culture and form dense cell clusters by two to three weeks. The medium was exchanged at three-day intervals and the cells were allowed to survive for three to four months. To obtain glial conditioned medium (GCM), cells were washed twice and then incubated overnight in F-12, either with or without FCS. The conditioned medium was removed and filtered through a $0.2 \mu \mathrm{m}$ low protein-binding syringe filter (Acrodisc, Gelman Sciences, Ann Arbor, MI, U.S.A.) to remove cellular debris. Protein determinations (Bradford method, bovine serum albumin standard; BioRad, Richmond, CA, U.S.A.) indicate that GCM typically has a protein concentration of about $225 \mu \mathrm{g} / \mathrm{ml}$.

\section{Optic nerve conditioned media}

Factors secreted by the goldfish optic nerve were collected as in our previous study ${ }^{35}$ using methods similar to those described earlier ${ }^{8,27}$ Goldfish were anesthetized by chilling to $4 \mathrm{C}$ and killed by cervical transection. Optic nerves and tracts were dissected free from eyes, tectal gray matter and connective tissue, and cut into $1-2 \mathrm{~mm}$ segments. Fragments from five optic nerves were incubated in $2.5 \mathrm{ml}$ HEPESbuffered L-15 medium (Gibco) for $3 \mathrm{~h}$ at $37^{\circ} \mathrm{C}$ in a $5 \% \mathrm{CO}_{2}$ environment, then filter-sterilized through a $0.2 \mu \mathrm{m}$ low protein-binding syringe filter (Acrodisc). Optic nerve conditioned medium (ONCM) prepared in this manner typically had a protein concentration of about $100 \mu \mathrm{g} / \mathrm{ml}$.

\section{Molecular separations}

ONCM and GCM underwent an initial size fractionation by ultrafiltration using molecular weight cut-off filters of 3000 (Amicon, Beverly, MA, U.S.A.) and then, in some cases, 1000 (Filtron, Northborough, MA, U.S.A.). In cases where the retentate was examined further, it was resuspended in the original volume of PBS and filtered again to remove residual low-molecular-weight components. Filtrates were concentrated $\times 10-20$ by lyophilization and then fractionated using high-performance liquid chromatography (HPLC). Reverse-phase HPLC was carried out on a $\mathrm{C}_{18}$ column (Synchropak RP-P, Synchrom, Inc.). Elution was achieved with a 40 min non-linear gradient from $100 \%$ Solvent A to $100 \%$ Solvent $\mathrm{B}$ at a constant flow rate of $1 \mathrm{ml} / \mathrm{min}$ according to the following equation: $\% \mathrm{~B}=100 \% \mathrm{~B}(t / 40)^{3}$, where $t$ is the elapsed time from injection and $\% B$ is the percentage of solvent $B$ at a given elapsed time $t$. Solvent A was $0.1 \%$ trifluoroacetic acid and Solvent B was $3: 2: 2(\mathrm{v} / \mathrm{v})$ isopropanol-acetonitrile-water containing $0.08 \%$ trifluoroacetic acid. Fractions of $1 \mathrm{ml}$ each were collected and lyophilized, redissolved in $0.1-1 \mathrm{ml}$ PBS and tested in the bioassay at $10-25 \%$ concentrations (based upon the original sample volume). Fractions found to contain biological activity were subjected to gel filtration chromatography on a Biosep Sec S2000 column (Phe- nomenex, Torrance, CA, U.S.A., run at $1 \mathrm{ml} / \mathrm{min}$ ) using $20 \%$ methanol in water as a buffer. Elution profiles of both the reverse-phase and gel-filtration columns were monitored spectrophotometrically at $210 \mathrm{~nm}$. Initial experiments collected fractions at $1 \mathrm{ml}$ intervals, whereas later ones collected discrete peaks or selected regions of peaks as visualized on the elution profile. Column fractions were lyophilized, resuspended in PBS and bioassayed.

Amino acid analysis and mass spectroscopy (MALDI) were carried out at the Harvard Microchemistry Facility under the supervision of Dr William Lane.

Experiments were carried out in accordance with protocols approved by Children's Hospital's Institutional Animal Use and Care Committee and the NIH Guide. The number of animals used was determined by the minimum required to obtain the tissues for cell cultures and for isolating sufficient quantities of the biologically active factors for reliable characterization.

\section{RESULTS}

\section{Effects of glial conditioned media on goldfish retinal ganglion cells}

In long-term cultures, glial cells migrate from the nerve fragments, proliferate and form a network-like carpet consisting predominantly of two cell types: elongated cells that are recognized by markers for oligodendrocytes and clusters of cells that show morphological features and antigenic properties characteristic of astrocytes ${ }^{2}$ (Fig. 1). Media containing factors secreted by these cultures (i.e. GCM), when tested in the bioassay, induced extensive outgrowth from retinal ganglion cells (Fig. 2b).

\section{The principal neurite-promoting factor in glial con- ditioned media coincides with axogenesis factor -1}

When GCM was subjected to ultrafiltration, fractions $>3000$ and $<3000$ molecular weight were both found to induce high levels of neurite outgrowth (Table 1). When each fraction was diluted 100-fold, the low-molecular-weight material still elicited $60 \%$ of the maximal response, while the high-molecularweight fraction elicited a $30 \%$ maximal effect. In other experiments, ${ }^{35}$ we have found that the low-molecular-weight fraction causes a maximal response when present at a $2 \%$ concentration. Since the average protein concentration of GCM is $c .225 \mu \mathrm{g}$ total protein $/ \mathrm{ml}$, maximal activity is attained at an overall protein concentration of $c .4 .5 \mu \mathrm{g} / \mathrm{ml}$. In contrast, ONCM was found in our previous study to have an overall protein concentration of $100 \mu \mathrm{g} / \mathrm{ml}$ and to exhibit full activity when diluted to $15 \%$. Hence, on a per $\mu \mathrm{g}$ protein basis, GCM is three to four times more active than ONCM. Another difference is that whereas ONCM has significantly higher levels of activity in the fraction $<3000$ than in the fraction $>3000,{ }^{35}$ the present results show that, in GMC, the two activities are more nearly equal. Since the lowmolecular-weight fraction may contribute more to axonal outgrowth in vivo, and since its size suggests that it is distinct from the known polypeptide growth factors, we have focused on the active factor in the fraction $<3000$. 

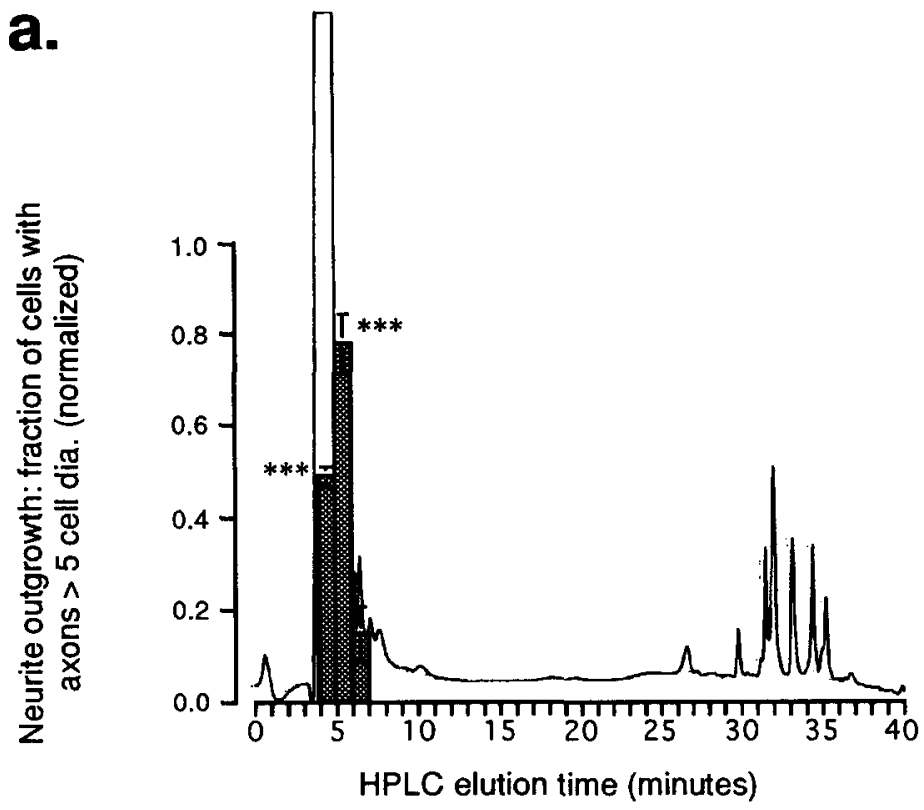

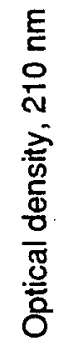

b.
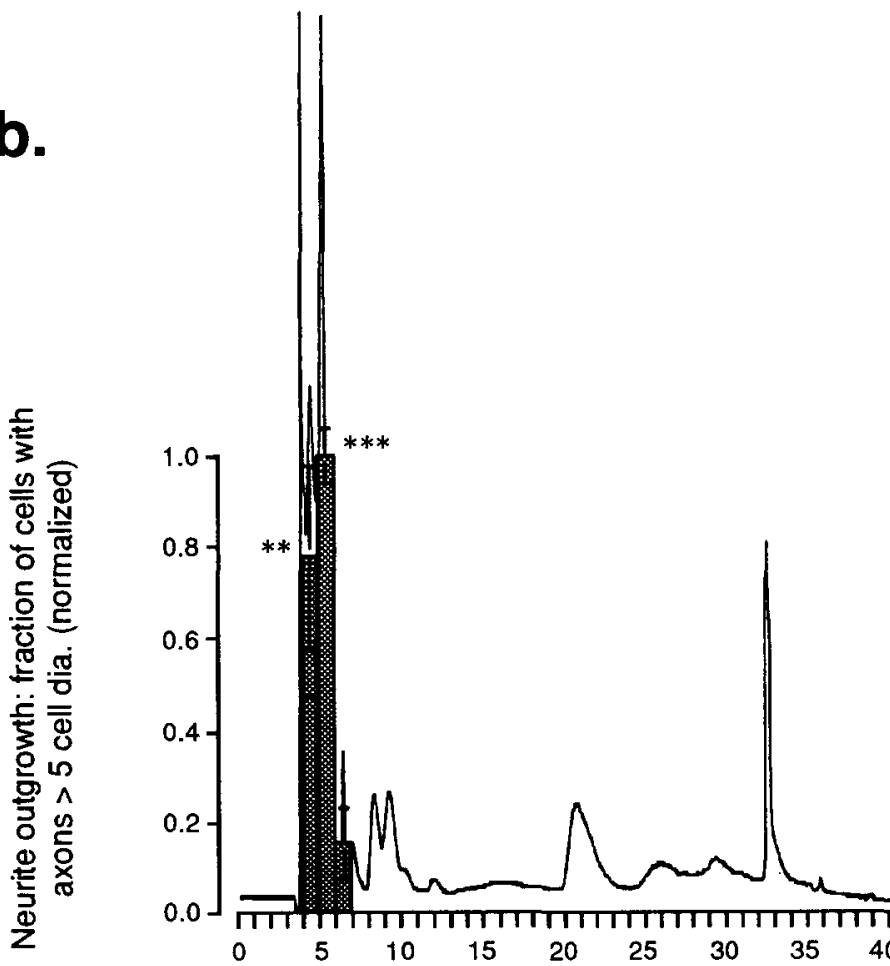

틀

HPLC column fractions, 1 min intervals

Fig. 4. Further separation of the low-molecular-weight factor from GCM and ONCM by reverse-phase HPLC. (a) Fraction D (from Fig. 3) was concentrated and applied to a $C_{18}$ reverse-phase HPLC column as described in the text. The principal components (visualized by absorbance at $210 \mathrm{~nm}$ ) eluted at $4-6 \mathrm{~min}$ and contained the neurite-promoting activity (fractions tested blind in quadruplicate at $10 \%$ concentrations). (b) The low-molecular-weight fraction from $\mathrm{ONCM}$ was applied to a $\mathrm{C}_{18}$ reverse-phase HPLC column. As with GCM, the principal components of ONCM (visualized by absorbence at $210 \mathrm{~nm}$ ) eluted at 4-6 min and contained the neurite-promoting activity (fractions tested at $25 \%$ concentrations) Significance of difference from negative controls indicated by asterisks: ${ }^{* *} P<0.01 ;{ }^{* * *} P<0.001$. 
When separated by size-exclusion HPLC, the low-molecular-weight fraction of GCM yielded the chromatogram shown in Fig. 3. In the bioassay, components eluting at $14-16 \mathrm{~min}$ were found to contain the neurite-promoting activity (Fig. 3: fractions tested at $10 \%$ concentration relative to starting volume; activity in peaks $\mathrm{D}$ and $\mathrm{E}$ vs $\mathrm{A}, \mathrm{B}$ and $\mathrm{C}$ significant at $P<0.001$ by one-way ANOVA with Bonferroni/Dunn correction). Fraction D, the principal part of the activity peak, was next subjected to reverse-phase HPLC, generating the elution profile shown in Fig. 4a. In the bioassay, only material eluting from the reverse-phase column at 4-5 $\mathrm{min}$ exhibited biological activity.

When the low-molecular-weight fraction $(<1000$ molecular weight) of ONCM fragments was subjected to reverse-phase HPLC, there was likewise a large absorbence peak in the unbound fraction, which eluted at 4-5 min. As with GCM, this fraction contained all of the neurite-promoting activity (Fig. 4b). The failure of the active components of either ONCM or GCM to bind to a hydrophobic matrix was confirmed using five HPLC $\mathrm{C}_{8}$ or $\mathrm{C}_{18}$ columns in three different laboratories (G-f. Hu, M-f. Gu and Harvard Microchemistry Facility).

Following reverse-phase chromatography, the biologically active fractions from both the GCM and the ONCM were re-chromatographed by gel-filtration HPLC, yielding the profiles shown in Fig. 5a and b, respectively. The major absorbence peaks of both GCM and ONCM appeared at $14.5 \mathrm{~min}$ (Fig. 5a, b). In the bioassay, the $14.5 \mathrm{~min}$ peaks of both GCM (Fig. 2c) and ONCM (Fig. 2d) contained the neuritepromoting activity (Fig. 5a, b) (by paired $t$-test, the active fraction from GCM vs other fraction significant at $P=0.003$; the active fraction of ONCM was significantly different from other fractions at $P=$ 0.0003; one-way ANOVA with Bonferroni/Dunn correction).
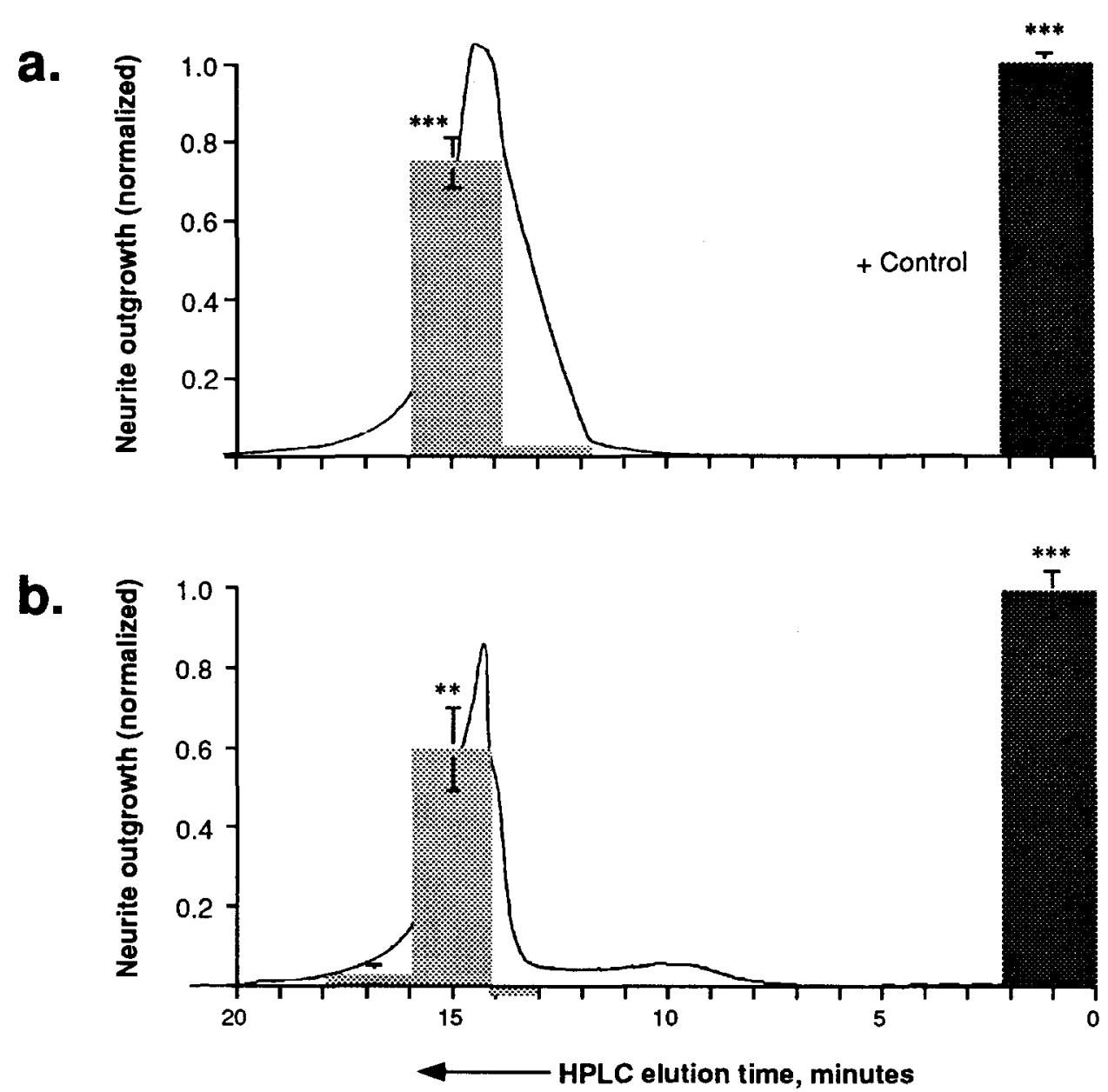

Fig. 5. Further separation of the active factor from ONCM and GCM by gel-filtration chromatography. Fractions from reverse-phase separations which contained the biologically active factors from GCM (Fig. 4a) and ONCM (Fig. 4b) were applied to a gel-filtration column as described in the text. The principal components of both GCM (a) and ONCM (b) eluted at 14-15 min (peak = 14.5 min) and contained the neurite-promoting activity, as evaluated in the bioassay in quadruplicate, blinded samples. Significance of difference from negative controls. ${ }^{* *} P<0.01 ;{ }^{* * *} P<0.001$. 


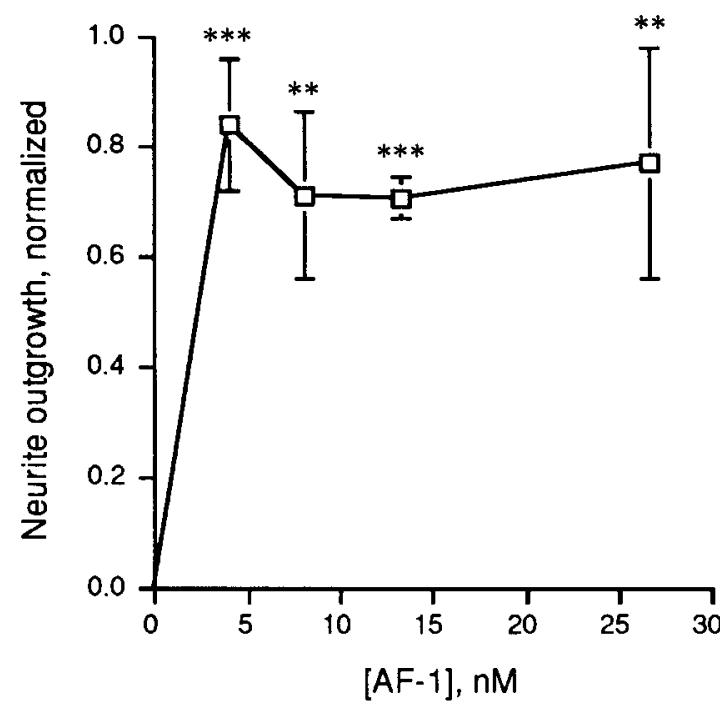

Fig. 6. Dose-response curve of AF-1. AF-1, isolated by sequential ultrafiltration, reverse-phase HPLC and gelfiltration HPLC, was bioassayed at increasing concentrations. Concentrations of AF-1 were converted from the amino acid concentration of the active fraction $(c .6 \mathrm{ng} / \mathrm{ml}$, Harvard Microchemistry Facility) to molarity based on the assumption that AF-1 is a peptide of molecular weight 702 . A half-maximal response was reached in the low nanomolar range. Significance of difference from negative controls.

$$
{ }^{* *} P<0.01 ;{ }^{* * *} P<0.001 \text {. }
$$

We found previously that the activity of AF-1 is degraded upon exposure to proteinase $\mathrm{K},{ }^{35}$ suggesting that it is a peptide. When submitted for amino acid analysis, the active fraction purified from $12 \mathrm{ml}$ of ONCM contained c. $700 \mathrm{ng}$ of amino acid. Mass spectroscopy (Harvard Microchemistry Laboratory) revealed a dominant component with a molecular weight of 702 , consistent with our previous size estimate of $600-900$ based upon the retention time of AF -1 by gel-filtration. These results indicate that, at full strength, the concentration of AF-1 is in the range of $75 \mathrm{nM}$. This material showed near-maximal activity when diluted 1:20 (Fig. 6; comparing the activity at $4 \mathrm{~nm} \mathrm{AF-1} \mathrm{vs} \mathrm{L-15} \mathrm{+} \mathrm{Medium} \mathrm{E} \mathrm{control,}$ $P=0.006$, paired $t$-test). Thus, even taking into account considerable amounts of loss during purification, it appears that AF-1 is active in the low nanomolar range.

Axogenesis factor -1 induces the same degree of axonal outgrowth irrespective of "priming"

To investigate the hypothesis that the glial-derived factors may be important for initiating axonal outgrowth, we compared the response of retinal ganglion cells that were "primed" to begin regenerating their axons in vivo vs naive retinal ganglion cells derived from previously intact animals. In the experiment shown in Fig. 7, four retinas from previously intact fish were pooled, as were four retinas from fish that had undergone bilateral optic nerve surgery 10 days previously. Both "naive" and "primed" retinal ganglion cells showed little spontaneous outgrowth in control media. In the presence of either total (unfractionated) conditioned medium or AF-1 alone (both at submaximal concentrations), neurons from "naive" and "primed" retinas showed similar levels of neurite outgrowth. Neither primed nor unprimed retinal ganglion cells showed any response to FCS present at a concentration of $10 \%$ (data not shown). The absence of a priming effect was confirmed in two additional studies.

\section{DISCUSSION}

The goldfish optic nerve has been a classic model for investigating the development and regeneration of complex neural systems. ${ }^{16}$ One fundamental difference between the glial environments of the fish and mammalian optic nerves is that, whereas mammalian oligodendrocytes inhibit axonal outgrowth, both in vivo and in culture, ${ }^{33}$ goldfish oligodendrocytes support extensive axonal outgrowth from both fish and mammalian retinal ganglion cells. ${ }^{2,3,40}$ The glial cultures used in these studies consist of about $80 \%$ oligodendrocytes and $20 \%$ astrocytes, and it is the former alone that were shown previously to be preferential substrates for axonal growth. ${ }^{2}$ One likely reason that goldfish oligodendrocytes are permissive for growth is that they express lower levels of inhibitory molecules on their surfaces than the comparable cell type in mammals; ; express an L1-like cell adhesion molecule. ${ }^{3,5.7,39}$ In

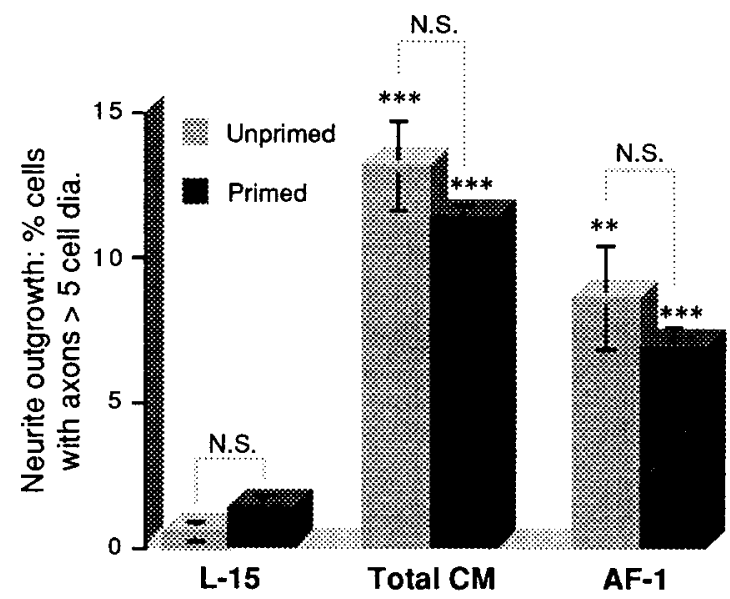

Fig. 7. The response of dissociated retinal ganglion cells is unaffected by a priming lesion. Retinas dissected from either previously intact fish (light shading) or fish which had undergone optic nerve surgery 14 days previously (to initiate the regenerative response in vivo; dark shading) were dissociated and cultured in the presence of either control (L-15) medium, unfractionated $\mathrm{ONCM}$ at a $10 \%$ concentration or a crude preparation of AF-1 (i.e. the low-molecular-weight fraction of ONCM at a $10 \%$ concentration). In all cases, the extent of neurite outgrowth was unaffected by a "priming" lesion (significance of difference from negative controls: ${ }^{* *} P<0.01 ;{ }^{* * *} P<0.001$; comparisons between primed and unprimed retinas indicated by dotted lines: N.S., not significant). 
addition to these properties, we show here that goldfish glia secrete soluble factors that are extremely potent in inducing retinal ganglion cells to extend processes.

Fragments of the goldfish optic nerve, when incubated in culture media for $3-4 \mathrm{~h}$, were shown previously to release two soluble factors that induce dissociated retinal ganglion cells to extend axons in culture. $^{35}$ The small neurite-promoting factor produced by glial cells in culture was shown here to be identical to the low-molecular-weight factor secreted from fragments of the optic nerve. In both cases, the active molecule is highly hydrophilic, as evidenced by its failure to bind to a reverse-phase $\mathrm{C}_{18}$ column, and elutes from a gel-filtration column with an apparent molecular weight of 700-900. In good agreement with this, the factor isolated here was estimated by mass spectroscopy to have a weight of 702. Preliminary studies indicate that AF-1 derived from either glial cultures or ONCM also promotes axonal outgrowth from retinal ganglion cells of the rat (Gu M-f. and Benowitz L., unpublished observations). Together, these findings indicate that (i) it is the glial cells of the optic nerve, most probably oligodendrocytes, that are the source of the factor AF-1; and (ii) this molecule may contribute to the preference of both mammalian and fish retinal ganglion cells to grow in close proximity to goldfish oligodendrocytes in culture. ${ }^{2}$ It will be interesting to examine whether mammalian oligodendroglia, in addition to expressing inhibitory factors, secrete a homolog of AF-1 at early stages of development. In addition to AF-1, the glial cultures secrete a larger neurite-promoting factor that may be the same as AF-2, a 10,000-15,000 molecular weight polypeptide which we described previously in media conditioned by fragments of optic nerve. One possibility that needs to be explored is whether the larger molecule is a precursor of AF-1.

Many studies have shown that fragments of goldfish retina, when explanted into culture, exhibit extensive outgrowth if the regenerative process had already begun in vivo one to two weeks earlier, but show little outgrowth otherwise. ${ }^{13,17,20,23,24,38}$ The failure of "unprimed" retinal explants to extend axons in culture suggests that a factor that is responsible for initiating regeneration in vivo is missing. One element that is absent in these studies is the glial cells of the optic nerve. The likelihood that factors secreted by optic nerve glia are important for initiating axonal outgrowth in vivo is supported by our finding that these factors will allow "naive", unprimed retinal ganglion cells to extend axons in culture to the same degree as cells which had begun to regenerate their axons in vivo 10-14 days earlier, the optimal interval for the priming phenomenon. ${ }^{26,29}$

\section{CONCLUSIONS}

This study demonstrates that, in goldfish, glial cells of the optic nerve secrete a low-molecular-weight factor that induces retinal ganglion cells to regenerate severed axons. This factor, which we term AF-1, is a highly hydrophilic molecule with an estimated molecular weight between 700 and 900 . It is effective in the low nanomolar range. AF-1 exerts an equally potent effect irrespective of whether retinal ganglion cells had been primed to begin regenerating their axons in vivo or not. We therefore conclude that AF-1 is likely to be one of the principal factors responsible for initiating axonal regeneration in vivo. Hence, establishing its molecular structure becomes an important priority.

Acknowledgements - This work was supported by a grant from the National Eye Institute (NIH EY 05690 to L. I. B.), with additional funding from the Deutsche Forschungsgemeinschaft (SFB 156 to C. S.) and the Boston Neurosurgical Foundation. The first two authors contributed equally to this study. We are grateful to Ulrike Binkle for technical assistance. J. M. S. and N. B. were Howard Hughes Medical Student Fellows. J. M. S. is currently at Yale Medical School and N. B. is in the Department of Neurosurgery, University of Michigan Medical Center.

\section{REFERENCES}

1. Aguayo A. J., Rasminsky M., Bray G. M., Carbonetto S., McKerracher L., Villegas-Perez M. P., Vidal-Sanz M. and Carter D. A. (1991) Degeneration and regeneration of injured neurons in the nervous system of adult mammals. Phil. Trans. R. Soc. Lond. Series B 331, 337-343.

2. Bastmeyer M., Bahr M. and Stuermer C. A. O. (1993) Fish optic nerve oligodendrocytes support axonal regeneration of fish and mammalian retinal ganglion cells. Glia 8, 1-11.

3. Bastmeyer M., Beckmann M., Schwab M. E. and Stuermer C. A. O. (1991) Growth of regenerating goldfish axons is inhibited by rat oligodendrocytes and CNS myelin but not by goldfish optic nerve tract oligodendrocyte-like cells and fish CNS myelin. J. Neurosci. 11, 626-640.

4. Bastmeyer M., Beckmann M., Schwab M. E. and Stuermer C. A. O. (1994) Similarities and differences between fish optic nerve/tract oligodendrocytes and Schwann cells. Glia 11, 300-314.

5. Bastmeyer M., Ott H., Leppert C. and Stuermer C. A. O. (1996) Fish E 587 glycoprotein, a member of the L1-family of cell adhesion molecules, participates in axonal fasciculation and the age-related order of ganglion cells in the goldfish eye. J. Cell Biol. 130, 969-976.

6. Battisti W. P., Shinar Y., Schwartz M., Levitt P. and Murray M. (1992) Temporal and spatial patterns of expression of laminin, chondroitin sulphate proteoglycan, and HNK-1 immunoreactivity during regeneration in the goldfish optic nerve. J. Neurocytol. 21, 557-573.

7. Blaugrund E., Bartsch U., Martini R., Schachner M. and Schwartz M. (1990) Immunological evidence that the neuronal adhesion molecule $\mathrm{L} 1$ is expressed in fish brain and optic nerve: possible association with optic nerve regeneration. Brain Res. 530, 239-244. 
8. Caday C. G., Apostilides P. J., Benowitz L. I., Perrone-Bizzozero N. I. and Finklestein S. P. (1989) Partial purification and characterization of a neurite-promoting factor from the goldfish optic nerve. Molec. Brain Res. 5, 45-50.

9. Caroni P. and Schwab M. E. (1988) Two membrane protein fractions from rat central myelin with inhibitory properties for neurite growth and fibroblast spreading. J. Cell Biol. 106, 1281-1288.

10. Dodd J. and Jessell T. M. (1988) Axon guidance and the patterning of neural projections in vertebrates. Science 242, 692-699.

11. Eitan S. and Schwartz M. (1993) A transglutaminase that converts interleukin-2 into a factor cytotoxic to oligodendrocytes. Science 261, 106-108.

12. Eitan S., Zisling R., Cohen A., Belkin M., Hirschberg D. L., Lotan M. and Schwartz M. (1992) Identification of an interleukin 2-like substance as a factor cytotoxic to oligodendrocytes and associated with central nervous system regeneration. Proc. natn. Acad. Sci. U.S.A. 89, 5442-5446.

13. Ford-Holevinski T. S., Hopkins J. M., McCoy J. P. and Agranoff B. W. (1986) Laminin supports neurite outgrowth from explants of axotomized adult retinal neurons. Brain Res. 28, 12l-126.

14. Giulian D., Allen R. L., Baker T. J. and Tomozawa Y. (1986) Brain peptides and glial growth. I. Glia-promoting factors as regulators of gliogenesis in the developing and injured central nervous system. J. Cell Biol. 102, 803-811.

15. Goodman C. and Shatz C. (1993) Developmental mechanisms that generate precise patterns of neuronal connectivity. Cell 72/Neuron 10, Suppl. 65-75.

16. Grafstein B. (1986) The retina as a regenerating organ. In The Retina, A Model for Cell Biology Studies, Part II (eds Adler R. and Farber D. B.), pp. 275-335. Academic Press, New York.

17. Hall C. M., Else C. and Schechter N. (1990) Neuronal intermediate filament expression during neurite outgrowth from explanted goldfish retina: effect of retinoic acid. J. Neurochem. 55, 1671-1682.

18. Harel A., Fainaru M., Shafer Z., Hernandez M., Cohen A. and Schwartz M. (1989) Optic nerve regeneration in adult fish and apolipoprotein A-1. J. Neurochem. 52, 1218-1228.

19. Hirsch S., Cahill M. A. and Stuermer C. A. O. (1996) Fibroblasts at the transection site of the injured goldfish optic nerve and their potential role during retinal axonal regeneration. J. comp. Neurol. (in press).

20. Hopkins J. M., Ford-Holevinski T. S., McCoy J. P. and Agranoff B. W. (1985) Laminin and optic nerve regeneration in the goldfish. $J$. Neurosci. 5, 3030-3038.

21. Jacobson M. (1991) Developmental Neurobiology, 3rd edn. Plenum, New York.

22. Johnson J. E. and Turner J. E. (1982) Growth from regenerating goldfish retinal cultures in the absence of serum or hormonal supplements: tissue extract effects. J. Neurosci. Res. 8, 315-329.

23. Landreth G. E. and Agranoff B. W. (1976) Explant culture of adult goldfish retina: effect of prior optic nerve crush. Brain Res. 118, 299-303.

24. Landreth G. E. and Agranoff B. W. (1979) Explant culture of adult goldfish retina: a model for the study of CNS regeneration. Brain Res. 161, 39-53.

25. McKerracher L., David S., Jackson D. L., Kottis V., Dunn R. J. and Braun P. E. (1994) Identification of myelin-associated glycoprotein as a major myelin-derived inhibitor of neurite outgrowth. Neuron 13, 805-811.

26. McQuarrie I. G. and Grafstein B. (1980) Effect of a conditioning lesion on optic nerve regeneration in goldfish. Brain Res. 216, 253-264.

27. Mizrachi Y., Rubinstein M., Kimhi Y. and Schwartz M. (1986) A neurotrophic factor derived from goldfish brain: characterization and purification. J. Neurochem. 46, 1675-1682.

28. Mukhopadhyay G., Doherty P., Walsh F. S., Crocker P. R. and Filbin M. T. (1994) A novel role for myelin-associated glycoprotein as an inhibitor of axonal regeneration. Neuron 13, 757-767.

29. Reich J. B., Burmeister D. W., Schmidt J. T. and Grafstein B. (1990) Effect of conditioning lesions on regeneration of goldfish optic axons: time course of the cell body reaction to axotomy, Brain Res. 515, 256-260.

30. Reichardt L. R. and Tomaselli K. J. (1991) Extracellular matrix molecules and their receptors: functions in neural development. A. Rev. Neurosci. 14, 531-570.

31. Salles F. J., Schechter N. and Strickland S. (1990) A plasminogen activator is induced during goldfish optic nerve regeneration. Eur. molec. Biol. Org. J. 9, 2471-2477.

32. Schnell L. and Schwab M. E. (1990) Axonal regeneration in the rat spinal cord produced by an antibody against myelin-associated neurite growth inhibitors. Nature 343, 269-272.

33. Schwab M. E. and Caroni P. (1988) Oligodendrocytes and CNS myelin are nonpermissive substrates for neurite growth and fibroblast spreading in vitro. J. Neurosci. 8, 2381-2393.

34. Schwab M. E., Kapfhammer J. P. and Bandtlow C. E. (1993) Inhibitors of neurite growth. A. Rev. Neurosci. 16, $565-596$.

35. Schwalb J. M., Boulis N. M., Gu M-f., Winickoff J., Jackson P. S., Irwin N. and Benowitz L. I. (1995) Two factors secreted by the goldfish optic nerve induce retinal ganglion cells to regenerate axons in culture. $J$. Neurosci. 15, $5514-5525$

36. Schwartz M. and Agranoff B. W. (1981) Outgrowth and maintenance of neurites from cultured goldfish retinal ganglion cells. Brain Res. 206, 331-343.

37. Sperry R. W. (1944) Optic nerve regeneration with return of vision in anurans. J. Neurophysiol. 7, 57-69.

38. Turner J. E., Schwab M. E. and Thoenen H. (1982) Nerve growth factor stimulates neurite outgrowth from goldfish retinal explants: the influence of a prior lesion. Devl Brain Res. 4, 59-66.

39. Vielmetter J., Lottspeich F. and Stuermer C. A. O. (1991) The monoclonal antibody E 587 recognizes growing (new and regenerating) retinal axons in the goldfish retinotectal pathway. $J$. Neurosci. 11, 3581-3593.

40. Wanner M., Lang D., Bandtlow C. E., Schwab M. E., Bastmeyer M. and Stuermer C. A. O. (1996) Re-evaluation of the growth permissive substrate properties of goldfish optic nerve myelin and myelin proteins. J. Neurosci. 15 , $7500-7509$ 